patients and their co-workers or vice versa. It is a major cause of sickness absenteeism among HCWs.

Influenza vaccination is one of the effective means of preventing influenza illness. It is usually carried out once or twice each year, depending on the predicted virus strains. Guidelines from the World Health Organisation (WHO) and many countries recommend influenza vaccination for HCWs. More importantly, as an infection control practice, vaccination can reduce transmission of influenza in healthcare settings, including protecting elderly and immunocompromised patients, who have higher mortality from complications of influenza. However, influenza vaccination rates among HCWs are universally low in many countries.

This study was conducted among nursing staff in two hospitals in Singapore. The aims were to understand the knowledge, perceived benefits, cultural values and behaviour of nursing staff towards influenza vaccinations. This study will help us understand the gaps and barriers towards influenza vaccination rates and in designing an effective influenza immunisation program in future.

\section{9b EMERGING INFECTIONS AND HEALTH CARE WORKERS IN THAILAND}

Adul Bandhukul. Nopparat Rajathanee Hospital, Bangkok, Thailand

10.1136/oemed-2018-ICOHabstracts.583

Thailand's population to doctor, dentist, registered nurse ratio in 2015 were 1 to 2035, 9352 and 436 respectively; with 117 infectious medical specialists and 63 occupational physicians.

In 2015, 89 hospitals had negative pressure rooms for Avian and other Influenza, Ebola and MERS.

The strategy to prevent emerging diseases among health care workers (HCWs) stresses on screening of patients who have fever and respiratory symptoms and who travelled from surveillance countries e.g. Africa for Ebola, Middle East for MERS; those who have chicken livestock at home or who had travelled in surveillance countries for Avian Flu.

During the first outbreak of Avian Influenza, HCWs did not know much about the illness and so there was fear among them. Subsequent release of information from the Ministry of Public Health, provision of Airborne Infection Isolation Rooms in almost every hospital, and assistance from occupational physicians and $\mathrm{OH}$ nurses allowed HCWs to work with greater confidence.

There were 25 cases of Avian influenza in with 17 fatalities.

In 2016 when there was outbreak of MERS-CoV, HCWs were given information on these diseases and generally did not fear to work with patients. However, a 2016 survey of nursing competency among final year nursing students showed that the lowest point in competency level was coping with emerging diseases. A report of $43 \mathrm{HCWs}$ with patient contact in a private hospital popular among Middle East patients stated that all used N-95 respirators (after respiratory fit testing) and other protective gears during their entire working period. All their serum specimens tested negative for MERScoV antibodies.

\section{C MONKEYING AROUND WITH MALARIA - BRUNEI DARUSSALAM'S EXPERIENCE}

${ }^{1}$ Khalifah Ismail* ${ }^{2}$ David Koh. ${ }^{1}$ Ministry of Health, Bandar Seri Begawan, Brunei Darussalam; ${ }^{2}$ PAPRSB Institute of Health Sciences, Universiti Brunei Darussalam

\subsection{6/oemed-2018-ICOHabstracts.584}

With the last local case of malaria reported in 1972, Brunei Darussalam has been declared 'Malaria-Free' by the World Health Organisation in 1987. In order to maintain the status attained, Brunei Darussalam has continued its surveillance through the Malaria Vigilance and Vector Control Unit in the Ministry of Health.

From the year 2000 until now, only indigenous cases of zoonotic Simian Malaria have been detected in people who are exposed in the line of duty namely border patrol officers, Armed Forces personnel and Department of Forestry officers.

Sixty four such cases have been reported in the past decade. The incidence has been minimised with the recommended use of prophylaxis for all personnel going on duty into the jungles, application of mosquito/insect repellants, and use of impregnated uniforms by Armed Forces personnel and impregnated bed nets in the camp sites.

\section{TRAVEL MEDICINE: MIGRANT WORKERS AND INTERNATIONAL SPREAD OF EMERGING INFECTIONS IN THE GLOBAL ECONOMY}

Marilou D Renales*. Minute Healt Care, Quezon City, Philippines

\subsection{6/oemed-2018-ICOHabstracts.585}

Aim of special session Discuss how globalisation results in emerging infections among migrant workers and how to prevent its transmission.

Globalisation may be defined as the transfer of businesses from the established markets to the developing economic markets. It is also evident that it has contributed to wider opportunities and enhanced equity in employment. However, there are effects of globalisation on occupational health such as in export processing zones, migrant workers, notification of work-related diseases, effects on health beyond the workplace and the under-recognition of the burden of occupational disease. This session will discuss the situation of travel medicine in the hiring of migrant workers.

${ }^{1}$ Xiuwen Sue Dong, ${ }^{2}$ Jean-Jacques Bernatas, ${ }^{3}$ Marilou Renales

${ }^{1}$ CPWR - The Centre for Construction Research and Training, Silver Spring, MD, USA

${ }^{2}$ Asian Development Bank, Mandaluyong City, Philippines

${ }^{3}$ Minute Health Care, Quezon City, Philippines

\section{3a DISPROPORTIONATELY AT RISK: IMMIGRANT WORKERS IN THE U.S. CONSTRUCTION INDUSTRY}

Xiuwen Sue Dong.

10.1136/oemed-2018-ICOHabstracts.586 
Immigrant workers play a significant role in the U.S. construction industry. This report summarises our recent findings about disparities in demographics, employment characteristics, health and healthcare, and disproportionate risk of workrelated injuries among these vulnerable workers. The statistics are obtained from several large national datasets in the U.S., including the Current Population Survey, American Community Survey, National Health Interview Survey, Medical Expenditure Panel Survey, the Census of Fatal Occupational Injuries, and the Survey of Occupational Injuries and Illnesses. Data from the Mexican Migration Project, an ongoing study of Mexican migration to the U.S., are also included. SAS 9.4 is employed for the data analysis.

The foreign-born population in the U.S. grew rapidly through mid-2000s, but slowed down since the Great Recession. Only $5 \%$ of current foreign-born construction workers arrived during the period of 2011 and 2013, whereas 10\% entered between 2005 and 2007. In 2015, about 2.4 million construction workers, or nearly a quarter of the industry workforce, were foreign-born; of which $84 \%$ were born in Latin American countries. It is estimated that nearly $75 \%$ of workers migrating from Mexico to the U.S. were undocumented or had false documentation on their first trip.

In general, immigrant construction workers are younger, less educated, and disproportionately work in high-risk occupations. These workers also lag behind other workers in income, health insurance coverage, and health services.

Work-related death rates for immigrant construction workers are consistently higher than other workers. However, this trend is not found in nonfatal injuries. Underreporting in nonfatal injuries is suggested. There are sizable disparities between immigrant construction workers and their native-born counterparts in the U.S. Given the rapid changes in the economy and the dangers associated with construction work, enhanced safety and health surveillance and intervention for immigrant construction workers is urgently needed.

\section{3b TB IN THE WORKPLACE AND BEYOND: CONTRIBUTION OF OCCUPATIONAL HEALTH SERVICES TO TB ELIMINATION IN THE ERA OF MOBILE WORKFORCE}

JJ Bernatas.

\subsection{6/oemed-2018-ICOHabstracts.587}

The challenges posed by TB have changed, especially with the threat of drug-resistant TB. Also, the growing mobility of people including workers is a main factor for disseminating TB faster and farther, thus rending its control even more difficult. While the main objective of occupational health services is to control the risk of TB contamination on the workplace, it should be also to reach out the local communities and thus leveraging the impact of the DOTS activities outside the workplace.

In high TB prevalence countries (HTBPC), TB is a hazard on the workplace, and should be integrated in HIRAC procedures, for having in place the necessary control measures. Cross-sectoral approach involving Ministries of Health and Labour contributes to achieve this objective, following the collaboration that ILO and WHO have already implemented. In
HTBPC, there is an urgent need to put in place measures on the workplace to scale up early diagnosis, adequate treatment, and better individual risk assessment based on personal history of mobility. Better coordination at intra-national, regional, and global levels is required to properly managed mobile workers infected with $\mathrm{TB}$, whether it is latent $\mathrm{TB}$ infection or active TB. Occupational Health Services have an important role to play to move this forward.

In low prevalence TB countries, there is an operational program towards TB elimination, where occupational health services have a role to play. In addition to social determinants, mobility plays an important role in these countries, and the wider availability of tests combined with powerful data management and utilisation of e-Health allows to fast track an outbreak and take the adequate control measures. Illegal foreign workers - usually migrants from HTBC - suffer lack of access to TB diagnosis and treatment, and may expose their families, local communities and coworkers in the workplace.

\section{C EMERGING INFECTIONS AND THE HEALTH RISKS OF MIGRANT WORKERS}

Marlou D Renales.

\subsection{6/oemed-2018-ICOHabstracts. 588}

Global movement of individuals, populations, and products is one of the major factors associated with the emergence and re-emergence of infectious diseases as the pace of global travel and commerce increases rapidly. Travel can be associated with disease emergence because (1) the disease arises in an area of heavy tourism, (2) tourists may be at heightened risk because of their activities, or (3) because they can act as vectors to transport the agent to new areas. Tourists may not stay in the country of destination for a significant period of time, however, workers spend considerable duration of stay due to overseas job contracts.

Migration across health and disease disparities influences the epidemiology of certain diseases globally and in nations receiving migrants. While specific disease-based outcomes may vary between migrant group and location, general epidemiological principles may be applied to any situation where numbers of individuals move between differences in disease prevalence.

Hence, there is a continued interrelationship between disease, travel and migration due to this global economic development affecting the workers who will be hired in the country of destination. The CDC defines 'emerging infectious diseases' as those infections that are increasing over time or threaten to increase. It also defines emerging infectious diseases as new infections resulting from new unknown pathogens, known infections which are increasing over new geographic areas, and known infections that are re-emerging as a result of both resistance to antimicrobial therapies and the failure of public health measures.

This paper discusses these infections related to travel of migrant workers as well as the health risks that they encounter. Current challenges exist in the prevention of transmission to other geographical areas of travel. 